\title{
ESTIMATION OF GUAIFENESIN FROM EXTENDED RELEASE DOSAGE FORM BY STABILITY INDICATING METHOD USING RP-HPLC TECHNIQUE
}

\author{
Emmanuel Madugula ${ }^{1}$ and Harikrishna Erothu ${ }^{1,2 *}$ \\ ${ }^{1}$ Department of Chemistry, Koneru Lakshmaiah Education Foundation (KLEF), Vaddeswaram, \\ Guntur-522 502, Andhra Pradesh, India. \\ ${ }^{2}$ Centre for Advanced Energy Studies (CAES), Koneru Lakshmaiah Education Foundation \\ (KLEF), Vaddeswaram, Guntur-522 502, Andhra Pradesh, India. \\ ${ }^{\square}$ Corresponding Author: harikrishnaiitm@gmail.com
}

\begin{abstract}
A simple, cost-effective, reproducible, robust stability-indicating liquid chromatography (LC) method is developed using reverse-phase mode and validated for the quantitative estimation of guaifenesin present in complex extendedrelease formulation dosage. Guaifenesin and its known impurities are well separated in this method; achieved baseline resolution by using C18 stationary phase and isocratic elution method. The validation of the analytical method was performed with parameters specificity, linearity, accuracy, precision, ruggedness and robustness using ICH guidelines. Evaluated linearity of method in the concentration range 60 to $180 \mu \mathrm{g} / \mathrm{mL}$ and the obtained correlation coefficient is within the limit (not less than 0.999).
\end{abstract}

Keywords: Guaifenesin, HPLC, Stability-indicating, Validation, Extended-release, Bronchitis

RASĀYAN J. Chem., Vol. 14, No.2, 2021

\section{INTRODUCTION}

Bronchitis is an infection of bronchial tubes, which carry air to the lungs. Inflammatory airway disorder diseases cause the production of mucus and obstruct the airways. Expectorants are generally used in treating bronchitis as it clears the mucus from the airways. Guaifenesin, (+)-3-(2-methoxyphenoxy)-propane-1, 2diol (Fig.-1) is a category of expectorant, widely employed to treat cough and nasal congestion caused by bronchitis and the common cold. Guaifenesin has one chiral center with empirical formula as $\mathrm{C}_{10} \mathrm{H}_{14} \mathrm{O}_{4}$, with a molecular mass of 198.21 and is a crystalline substance, slightly gray or white color and is bitter. The expectorant properties of guaifenesin primarily work by thinning of bronchial secretion and loosening mucus in the airways, clearing congestion, and suitable for the symptomatic relief of breathing conditions. ${ }^{1}$ Guaifenesin shows effects across different types of respiratory conditions like acute bronchitis, chronic respiratory conditions and rhinosinusitis. Guaifenesin mainly effects to decrease the production of mucus, other cough symptoms and nasal congestion. Guaifenesin is considered a safe and effectual expectorant in treating mucus-related respiratory disorder symptoms in acute bronchitis.

Daily multiple doses of immediate-release dosage formulations are needed to maintain the therapeutic effect for 24 hours. To overcome this, extended-release guaifenesin tablet formulations are developed for prolonged efficacy, providing more therapeutic effect with 12-hourly dosing compared to instant release dosage forms and reducing the frequency of dosing.

In literature, several high-performance liquid chromatography methods of assay for estimation of guaifenesin in solid and liquid oral dosage delivery forms by HPLC ${ }^{2-22}$ and methods in human plasma ${ }^{23-26}$ are reported. From the literature survey and further study, we have developed a stability-indicating, simple, cost-effective, reproducible, rugged, robust, reverse-phase liquid chromatography method for the quantitative estimation of guaifenesin in the presence of impurities in the complex extended-release formulation matrix. The developed liquid chromatography method validation was performed with the parameter's precision, specificity, accuracy, linearity, ruggedness, solution stability and robustness. Force degradation stress study was conducted on drug product and placebo to show the discrimination of the 
method considered as stability-indicating method. These stress studies are performed based on the ICH guidelines. ${ }^{27-29}$

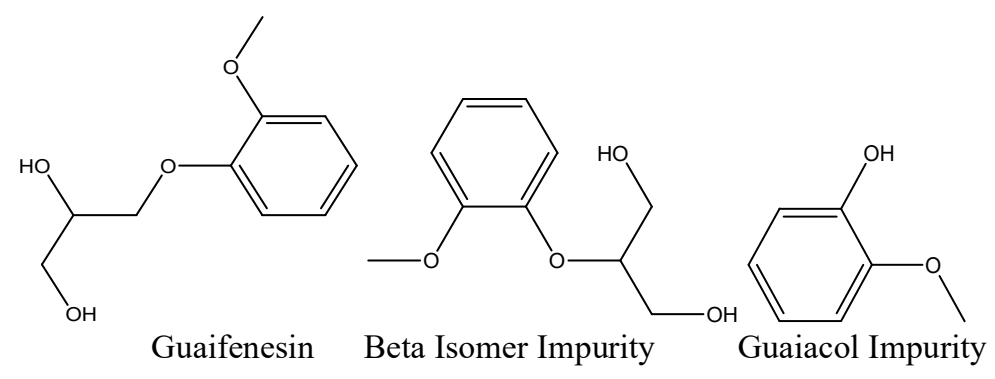

Fig.-1: Chemical Structures of Guaifenesin, Beta Isomer Impurity and Guaiacol Impurity

\section{EXPERIMENTAL}

\section{Material and Methods}

The methanol (Grade: HPLC) and dihydrogen potassium phosphate (Grade: AR) and ortho-phosphoric acid (Grade: AR) are purchased from Merck. Millipore purification system was used to obtain highly pure water. The reverse-phase HPLC method was used to estimate the Guaifenesin in the extended-release dosage form. Developed and the optimized procedure was validated with specificity, accuracy, precision, linearity, solution stability, ruggedness, and robustness. Chromatographic conditions were discussed below.

\section{Equipment}

The equipment used to perform the chromatographic analysis is Waters Alliance HPLC (2695) with UVvisible detector (2489) or Photo Diode Array detector (2998) or Agilent's 1200 series DAD detector, quaternary pump, degasser, and autosampler. The Processing of chromatograms was done by using Empower 2 software. A water bath (Cintex) was used in hydrolysis studies. The photostability chamber (Make: Sanyo) is used to perform photostability studies. A dry air oven (Make: Cintex) is used for thermal stability studies. The $\mathrm{pH}$ meter (Make: Mettler-Toledo) is used to check the $\mathrm{pH}$ of the solutions.

\section{Chromatographic Conditions}

The method developed using C18 stationary phase, Hypersil BDS column (4.6 x $150 \mathrm{~mm}, 5 \mu \mathrm{m})$ and the mobile phase comprises 60 volumes of potassium dihydrogen phosphate $0.02 \mathrm{M}$ (pH adjusted to 3.0) and 40 volumes of methanol. Filtered the mobile phase using $0.45 \mu \mathrm{m}$ dura pore hydrophilic membrane filters and degassed. Diluent was prepared using 60 volumes of water and 40 volumes of methanol. The flow rate of the mobile phase was kept as $1.0 \mathrm{~mL} / \mathrm{min}$. and $40^{\circ} \mathrm{C}$ temperature maintained for column oven. Observed the peaks at a wavelength of $271 \mathrm{~nm}$ with $10 \mu \mathrm{l}$ of sample injection volume.

\section{Standard Preparation}

The standard stock of Guaifenesin was prepared by weighing and transferred accurately $60 \mathrm{mg}$ into a 100 $\mathrm{mL}$ volumetric flask, dissolved in diluent using sonication and made up to the mark with diluent $(0.6$ $\mathrm{mg} / \mathrm{mL}$ ). Further prepared standard by diluting $10 \mathrm{~mL}$ of the standard stock transferred into $50 \mathrm{~mL}$ flask and made up to mark with diluent $(0.12 \mathrm{mg} / \mathrm{mL})$.

\section{Test Preparation}

Fine powder of tablets was made using mortar and pestle. Weighed and transferred sample equivalent to $600 \mathrm{mg}$ of Guaifenesin into a $250 \mathrm{~mL}$ flask, added $150 \mathrm{~mL}$ diluent. Kept on sonication for 15 minutes and made up to the mark with diluent. Centrifuged the above solution at 4000 RPM. Further pipette and transferred $5.0 \mathrm{~mL}$ of clear centrifugate into $100 \mathrm{~mL}$ volumetric flask and diluted up to the mark with diluent $(0.12 \mathrm{mg} / \mathrm{mL})$.

\section{HPLC Method Development}

\section{RESULTS AND DISCUSSION}

Method development was initiated based on the polarity of molecules and functional groups. Guaifenesin has one chiral center and its enantiomers. Guaifenesin is soluble in water, chloroform, alcohol, propylene 
glycol, and sparingly soluble in glycerin. By using UV spectroscopy, scanned the standard solution from $200 \mathrm{~nm}$ to $400 \mathrm{~nm}$ to find lambda $(\lambda)$ maxima. Based on the UV spectroscopic result evaluation, HPLC method optimization was done at lambda $(\lambda)$ maxima of around $271 \mathrm{~nm}$. The development study aims to estimate guaifenesin from a complex extended-release formulation matrix, which should be specific, separate from all known impurities and unknown degradation products. Various attempts are made to extract guaifenesin from the polymer-based complex matrix and got a good resolution from all known impurities and unknown degradation products. Numerous attempts are made with the mobile phase having different buffer $\mathrm{pH}$ and different methanol composition in the mobile phase and using different stationary phase columns like $\mathrm{C} 18$ and $\mathrm{C} 8$. To get a good resolution between guaifenesin and its known and unknown degradation compounds, the stationary phase (C18) having end-cap was used. The mobile phase was optimized comprising a mixture of solvent in the composition of 60 volumes of potassium dihydrogen phosphate $0.02 \mathrm{M}$ (pH adjusted to 3.0) and 40 volumes of methanol. The eluted compounds are observed at the wavelength of $271 \mathrm{~nm}$ with $1.0 \mathrm{~mL} /$ minute as flow rate and temperature of the column at $40{ }^{\circ} \mathrm{C}$.

\section{HPLC Method Development/Optimization Trial-1}

Prepared mobile phase A (Buffer) by dissolving $1.36 \mathrm{gm}$. of potassium dihydrogen orthophosphate in 1000 $\mathrm{mL}$ of Milli-Q-Water, used methanol as mobile phase $\mathrm{B}$, acetonitrile as mobile phase $\mathrm{C}$ in the composition of 50:15:35 vol $/ \mathrm{vol} / \mathrm{vol}$ respectively. Water and methanol of $60: 40 \mathrm{vol} / \mathrm{vol}$ ratio were used as diluents. Used column (Phenomenex) with stationary phase C18, 150x4.6 mm, $5 \mu \mathrm{m}$ and with the flow of $1.0 \mathrm{~mL} /$ minute. The temperature of the column oven was kept at $25^{\circ} \mathrm{C}$ and observed the peaks at a wavelength of $271 \mathrm{~nm}$ with sample injection volume as $10 \mu 1$.

\section{Observation}

Observed all three peaks Beta-Isomer, Guaifenesin and Guaiacol were eluted with retention at 1.60 minutes, 1.87 minutes, and 4.55 minutes. The peaks of Beta isomer and Guaifenesin were eluted in zero volume. Further optimization by decreasing of solvent ratio in the mobile phase is needed to increase the retention of beta isomer, guaifenesin peaks and get more resolution between peaks. Development trial impurity spiked test chromatogram is shown in Fig.-2.

\section{HPLC Method Development/Optimization Trial-2}

Mobile phase A was prepared using Potassium dihydrogen phosphate and adjusted $\mathrm{pH}$ to 3.0 and methanol in the composition of 50:50 v/v respectively. Water: methanol of 60:40 vol $/ \mathrm{vol} \mathrm{ratio}$ was used as diluent. Using Phenomenex column with C18 stationary phase, $150 \mathrm{x} 4.6 \mathrm{~mm}, 5 \mu \mathrm{m}$ with $1.0 \mathrm{~mL} /$ minute as flow rate. The column was maintained at $25{ }^{\circ} \mathrm{C}$ temperature and observed peaks at detection of $271 \mathrm{~nm}$. Using sample injection volume as $10 \mu \mathrm{l}$.

\section{Observation}

From impurities spiked sample chromatogram observed the peaks Beta-Isomer, Guaifenesin and Guaiacol are eluted with retention at 2.89 minutes, 3.26 minutes and 6.10 minutes. Less resolution was observed between Beta-Isomer and Guaifenesin peaks. To get more resolution between Beta-Isomer and Guaifenesin peaks further mobile phase solvent composition needs to optimize. Development trial impurity spiked test chromatogram is shown in Fig.-3.

\section{HPLC Method Development/Optimization Trial-3}

Mobile phase A ( $\mathrm{pH} 4.5$ buffer) preparation was done by dissolving $6.8 \mathrm{gm}$. of potassium dihydrogen orthophosphate in $1000 \mathrm{~mL}$ of Milli-Q-Water, methanol as mobile phase B in the composition of 55:45 v/v respectively. Water: methanol of $60: 40 \mathrm{v} / \mathrm{v}$ ratios was used as diluent. Column Xterra C18, 150x4.6mm, $5 \mu \mathrm{m}$ with $1.0 \mathrm{~mL} /$ minute as flow rate. The maintained temperature of the column at $40{ }^{\circ} \mathrm{C}$ and peaks are observed at lambda max of $271 \mathrm{~nm}$ with sample injection volume as $10 \mu 1$.

Observation: By changing the column and $\mathrm{pH}$ of the mobile phase, Beta-Isomer, Guaifenesin and Guaiacol peaks are eluted with retention at 2.39 minutes, 2.60 minutes and 4.43 minutes. Observed resolution 
between Beta-Isomer and Guaifenesin less than 2.0. Further optimization is needed to change the HPLC column to get a resolution greater than 2.0. Development trial impurity spiked test chromatogram is shown in Fig.-4.

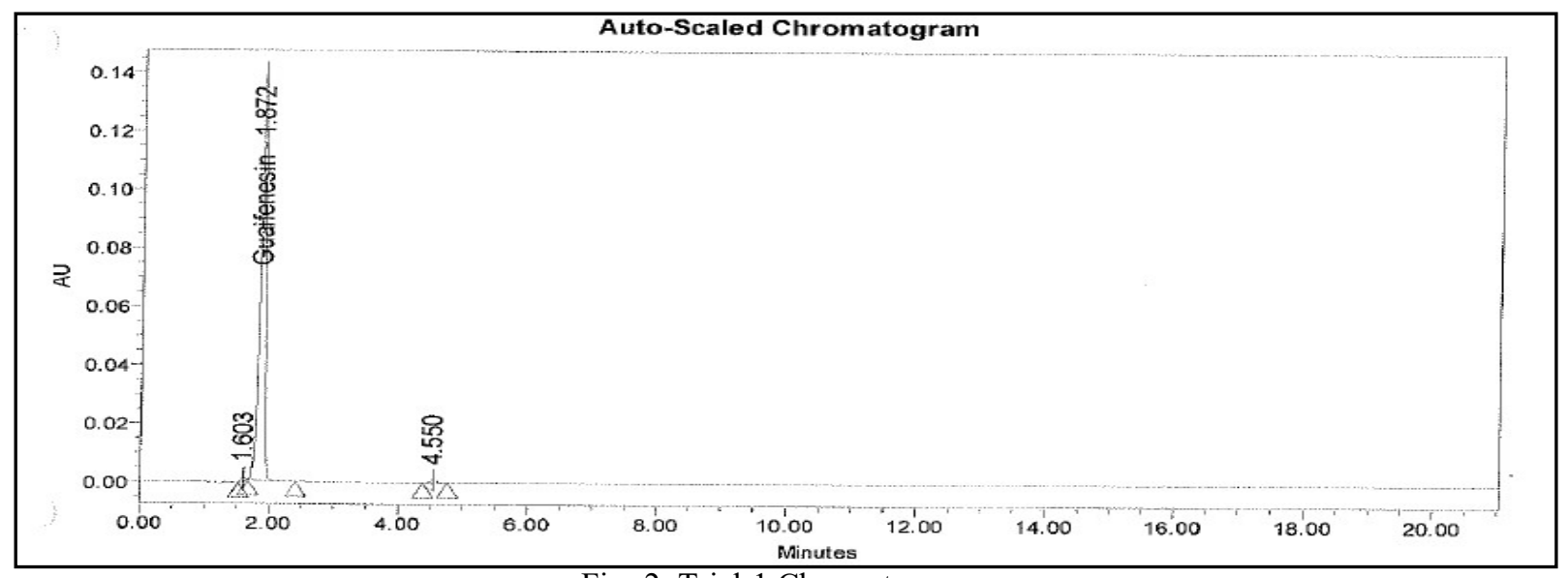

Fig.-2: Trial-1 Chromatogram

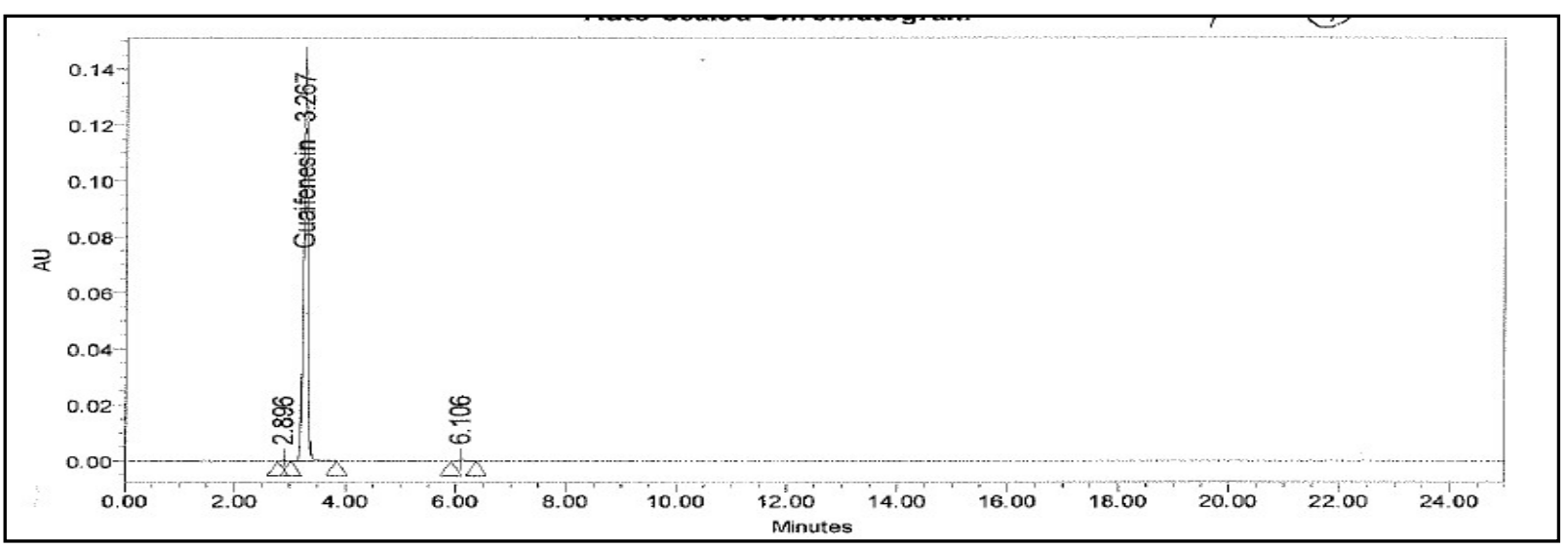

Fig.-3: Trial-2 Chromatogram

\section{HPLC Method Development/Optimization Trial-4}

The mobile phase was prepared in the composition of 60 volumes of dihydrogen potassium phosphate buffer $\mathrm{pH} 3.0$ and 40 volumes of methanol. Water and methanol used as a diluent in the composition of $60: 40 \mathrm{ml} \mathrm{vol} / \mathrm{vol}$ respectively. Column Hypersil BDS C18, 150x4.6mm, $5 \mu \mathrm{m}$ with $1.0 \mathrm{~mL} /$ minute as flow rate, column temperature at $40{ }^{\circ} \mathrm{C}$ and observed peaks at detection of $271 \mathrm{~nm}$ with sample injection volume as $10 \mu 1$.

Observation: After changing the column and increasing temperature the resolution between Beta-Isomer and Guaifenesin increased to 3.0. Observed Beta-Isomer, Guaifenesin and Guaiacol peaks with tailing factor is 1.0 and theoretical plates above 9000 . The three peaks were well resolved, with retention of BetaIsomer at 2.72 minutes, Guaifenesin at 3.10 minutes and Guaiacol at 5.67 minutes. Further optimization is needed to decrease the retention time of guaiacol and total runtime. Development trial impurities spiked test chromatogram is shown in Fig.-5.

\section{Validation of the Method}

The developed method to estimate Guaifenesin from a complex extended-release formulation matrix was validated as per guidelines of the International Council for Harmonization (ICH). ${ }^{27-29}$ The following validation parameters were executed: Specificity, linearity, accuracy, precision, ruggedness, solution stability and robustness. 


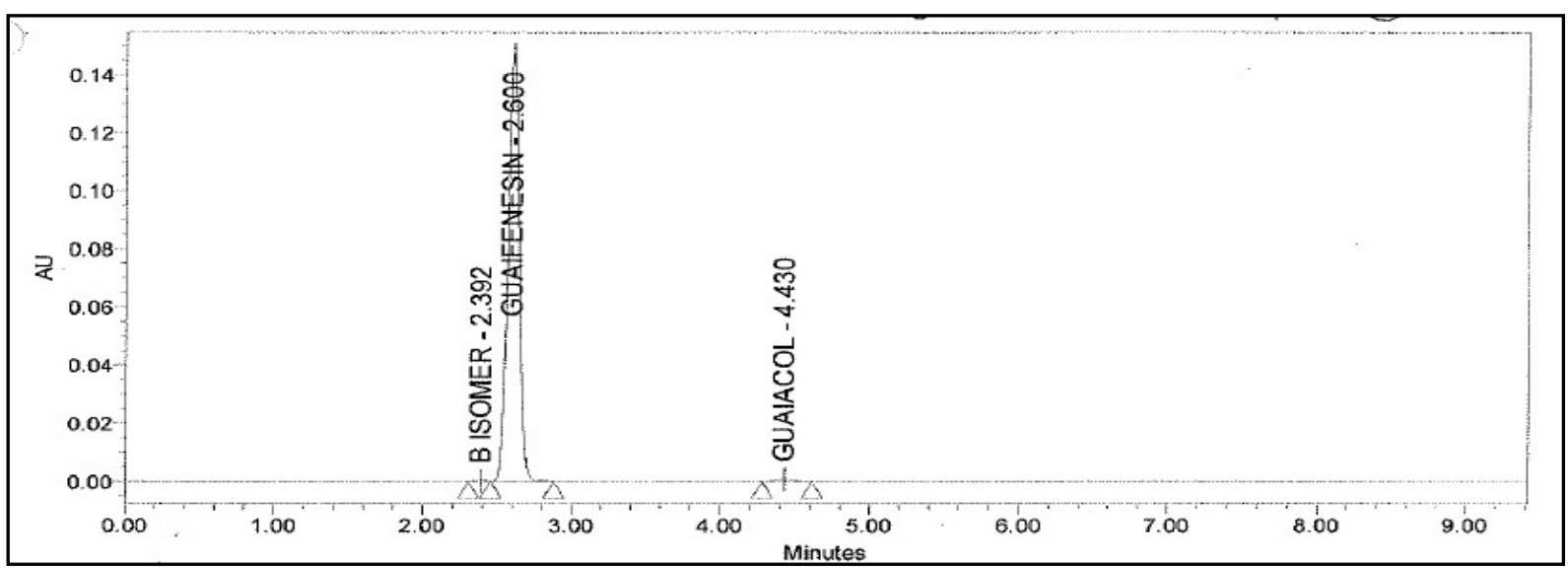

Fig.-4: Trial-3 Chromatogram

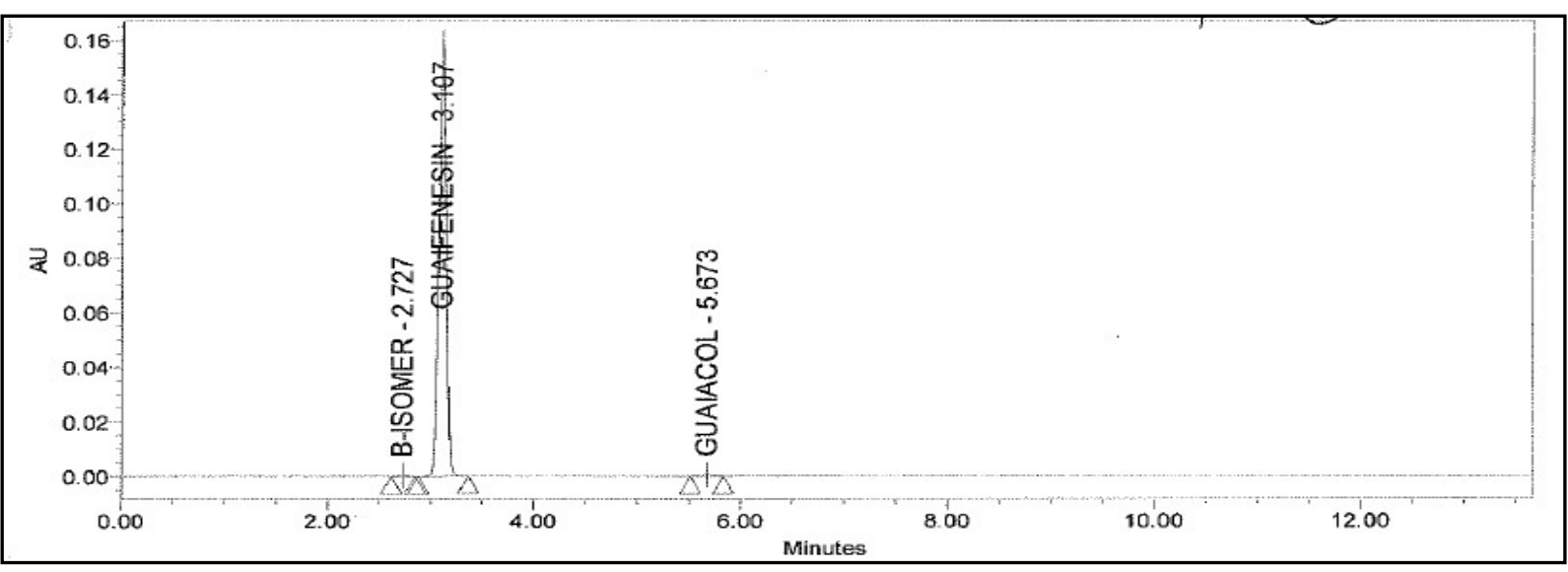

Fig.-5: Trial-4 Chromatogram

\section{Method Validation Summary \\ System Suitability}

The suitability parameters are evaluated for the standard solution as per the standard test procedure. The standard solution was prepared using Guaifenesin working standard as per the test procedure and injected into the HPLC system. A blank, standard solution of five replicates is injected into the HPLC system and evaluated for the system suitability. System suitability results are within acceptable limits and found satisfactory. The tailing factor obtained from the standard solution for the Guaifenesin peak is 1.1. The average theoretical plate count obtained from the standard solution for Guaifenesin peak is 9605 . The relative standard deviation for Guaifenesin peak areas from the five replicate injections is $0.1 \%$. The blank is shown in Figure-6 and the standard solution is shown in Fig.-7.

\section{Precision}

Method precision evaluation was done using six individual assay test preparations of the Guaifenesin ER Tablet and performed analysis according to the test method. The \% assay and the relative standard deviation of Guaifenesin are found within the acceptable limits. Performed intermediate precision using different instruments (HPLC), different columns, different analysts and different days. The $\%$ assay and the relative standard deviation of Guaifenesin are found within the acceptable limit (NMT 2.0\% RSD). The precision and intermediate precision results are shown in Table-1.

\section{Specificity}

Specificity is to check the interference from placebo, blank and impurities from degradation studies. Stress study testing for Acid, base, peroxide oxidation, water, photo, thermal, and humidity conditions was performed. 
RASĀYAN J. Chem.

Vol. 14 | No. 2 |1087-1097| April - June | 2021

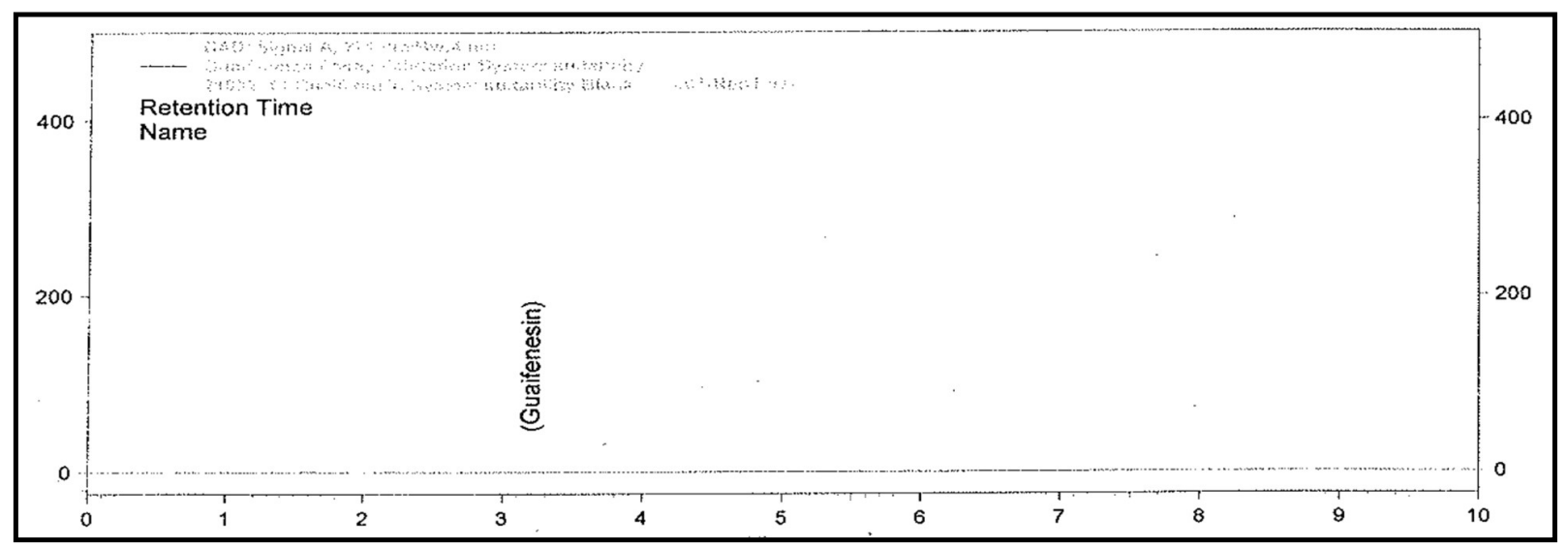

Fig.-6: Typical Chromatogram of Blank

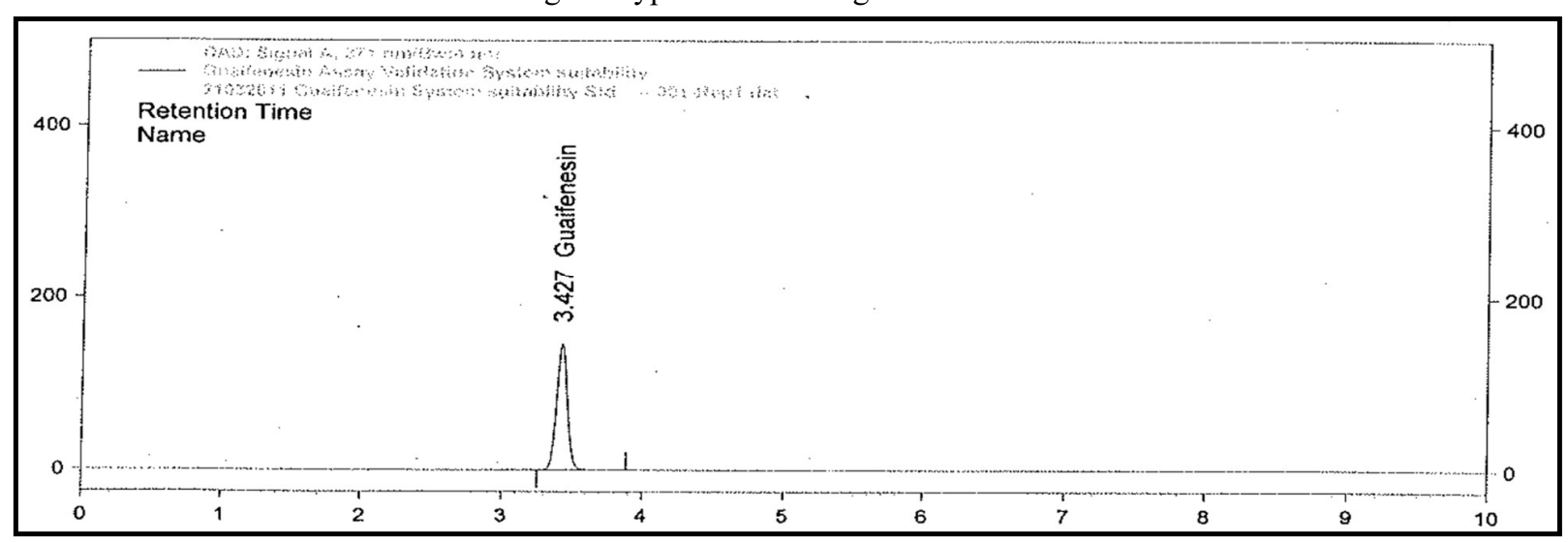

Fig.-7: Typical Chromatogram of Standard

Table-1: Guaifenesin - Precision and Intermediate Precision Results

\begin{tabular}{c|c|c}
\hline Test Preparation & Precision \% Assay & Intermediate \% Assay \\
\hline 1 & 99.93 & 100.92 \\
\hline 2 & 100.92 & 102.72 \\
\hline 3 & 100.87 & 101.34 \\
\hline 4 & 100.94 & 99.85 \\
\hline 5 & 100.75 & 101.40 \\
\hline 6 & 100.57 & 99.40 \\
\hline Mean & 100.66 & 100.94 \\
\hline \%RSD & 0.4 & 1.1 \\
\hline
\end{tabular}

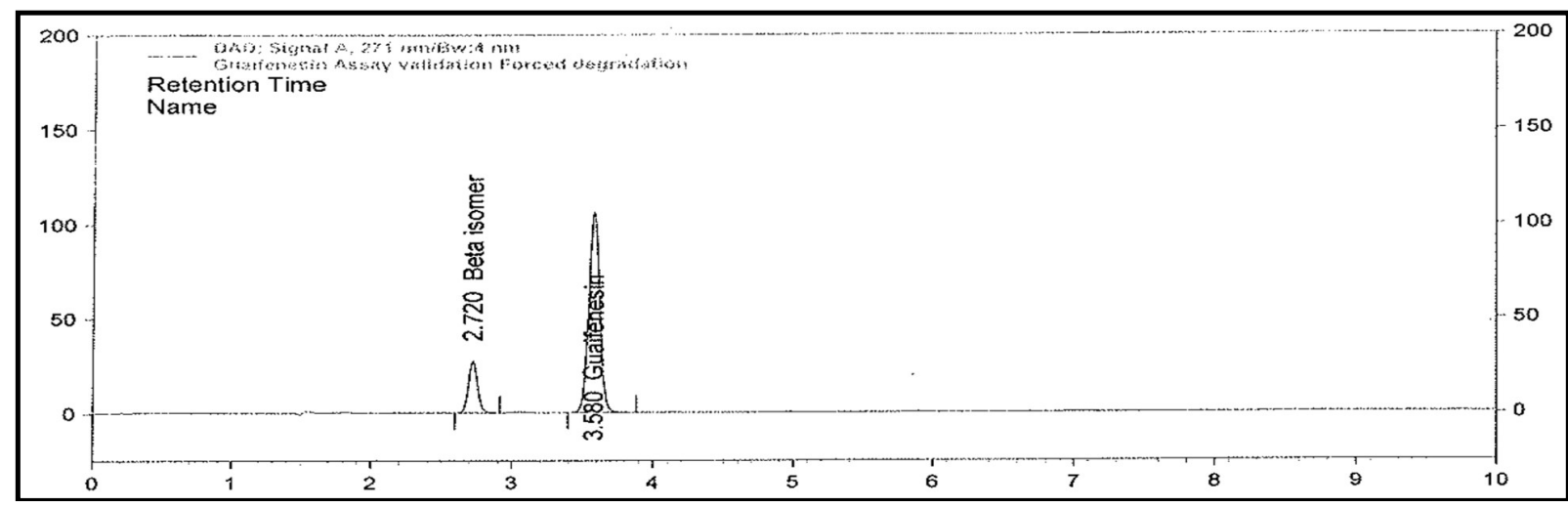

Fig.-8: Typical Chromatogram of Acid Stress Test 
RASĀYAN J. Chem.

Vol. 14 | No. 2 |1087-1097| April - June | 2021

In Table-2 all stress study conditions were listed. The stress study conditions for all test samples results are represented in Figure-8 to 12. To check specificity, injected all stressed samples into the HPLC system connected with detector photodiode array as per test method. Degradant peaks are well resolved from the Guaifenesin peak in all stressed sample chromatograms. The peak purity of Guaifenesin was evaluated for all the stressed samples using Agilent ezchrom analytical software. In all stress conditions of forced degraded samples, the peak purity was found more than 0.99 (limit: not less than 0.99 ). The results indicate no interference was observed from blank, placebo and degradants in quantitating the Guaifenesin in ER tablet. Hence, this discriminating nature of the method is considered as "Stability Indicating".

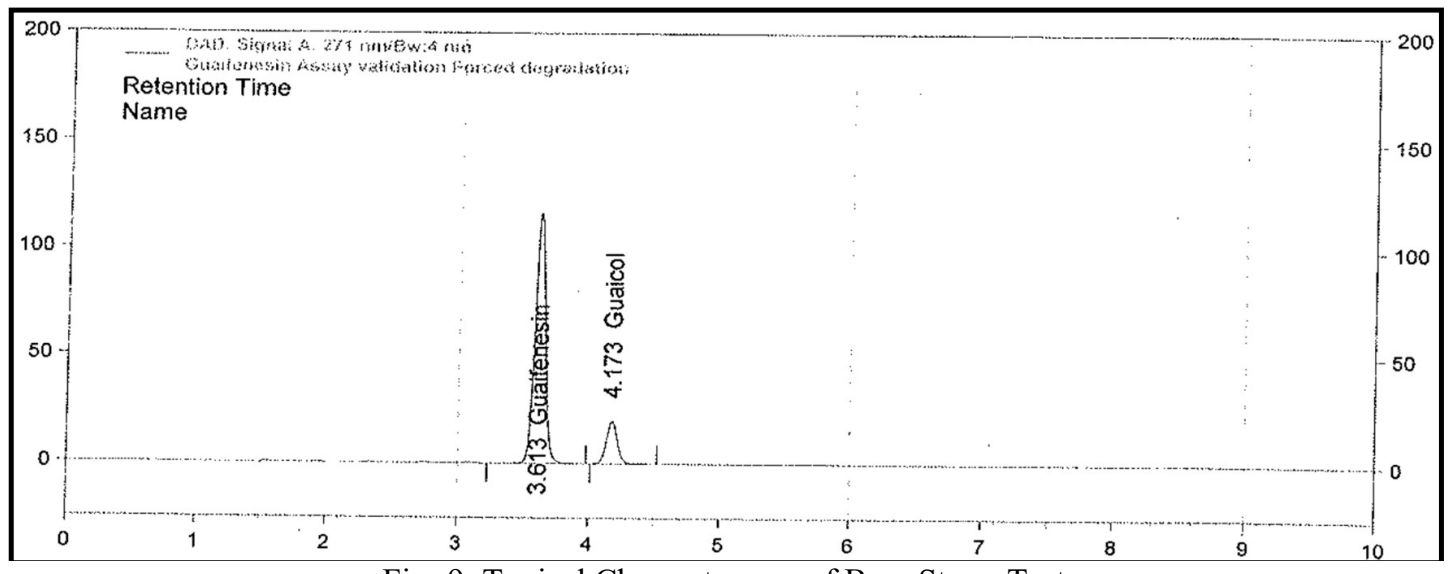

Fig.-9: Typical Chromatogram of Base Stress Test

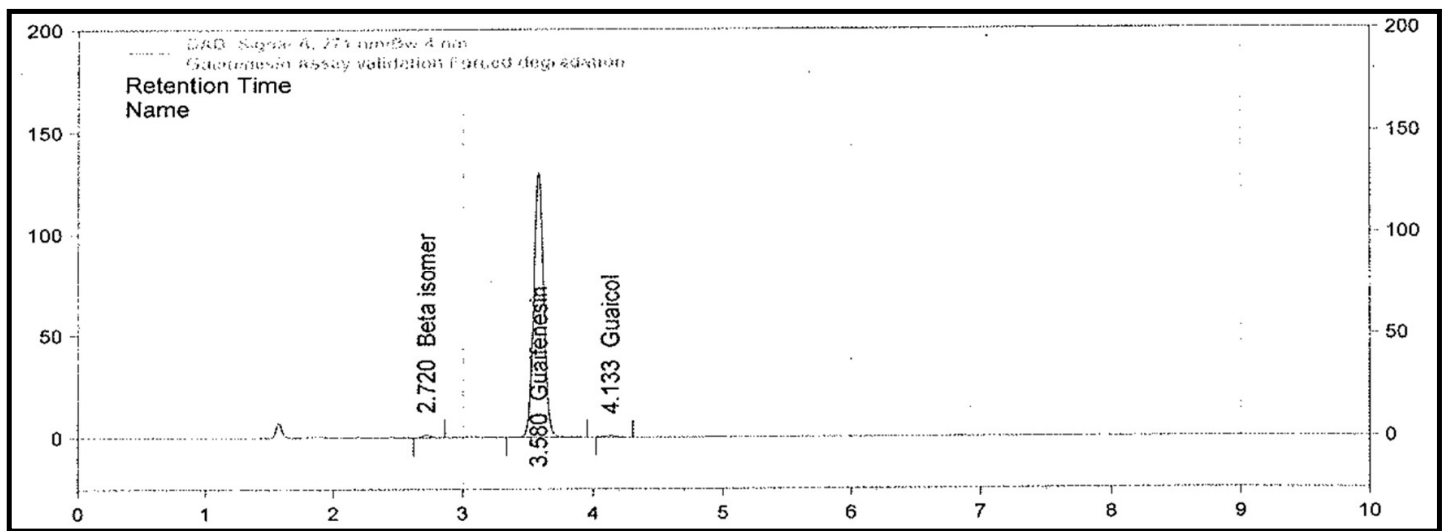

Fig.-10: Typical Chromatogram of Peroxide Stress Test

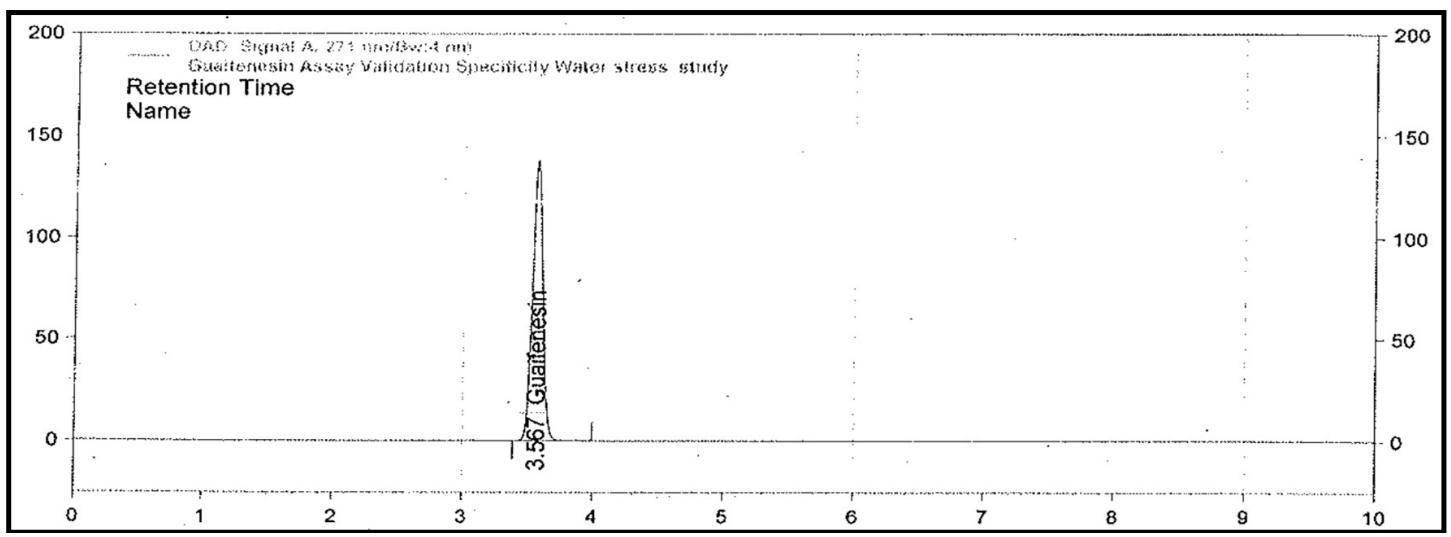

Fig.-11: Typical Chromatogram of Water Stress Test 
RASĀYAN J. Chem.

Vol. 14 | No. 2 |1087-1097| April - June | 2021

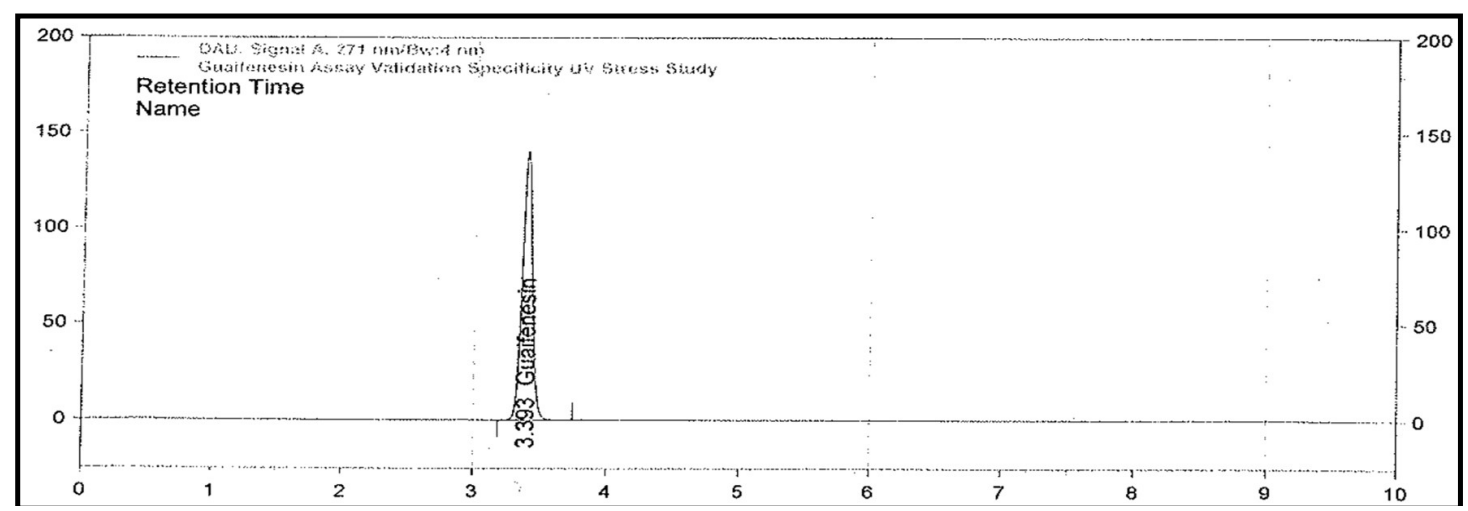

Fig.-12: Typical Chromatogram of Photolytic (UV/Visible Light) Stress Test

Table-2: Specificity Stress Study Conditions

\begin{tabular}{c|c}
\hline Stress parameter & Stress Conditions \\
\hline Acid stress & $5 \mathrm{~N} \mathrm{HCl}$ for 3 hours at $60^{\circ} \mathrm{C}$ \\
\hline Base stress & $5 \mathrm{~N} \mathrm{NaOH}$ for 12 hours at $60^{\circ} \mathrm{C}$ \\
\hline Peroxide stress & $10 \%$ for 6 hours at $60^{\circ} \mathrm{C}$ \\
\hline Water stress & For 12 hours at $60^{\circ} \mathrm{C}$ \\
\hline Photo stress & 200 -watt hours $/ 2 \mathrm{~m}-1.2 \mathrm{~m} \mathrm{Lux} \mathrm{hours} \mathrm{for} 7$ days \\
\hline Thermal stress & At $50^{\circ} \mathrm{C}$ for 7 days \\
\hline Humidity stress & At $85 \%$ RH for 7 days \\
\hline
\end{tabular}

Table-3: Specificity Stress Study Results

\begin{tabular}{c|c|c}
\hline Stress Condition & \% Degradation & Peak Purity \\
\hline Acid stress & 16.345 & 1.00 \\
\hline Base stress & 15.185 & 1.00 \\
\hline Peroxide stress & 1.465 & 1.00 \\
\hline Water stress & Nil & 1.00 \\
\hline Photo stress & Nil & 1.00 \\
\hline Thermal stress & Nil & 1.00 \\
\hline Humidity stress & Nil & 1.00 \\
\hline
\end{tabular}

\section{Linearity}

By diluting the guaifenesin standard stock solution to the required concentrations, linearity solutions are prepared. Linearity graph of guaifenesin confirmed by plotting a linear curve between concentrations versus peak response and calculated the correlation coefficient. Prepared five concentration solutions of Guaifenesin working standard in the linear range of $60 \mu \mathrm{g} / \mathrm{mL}$ to $180 \mu \mathrm{g} / \mathrm{mL}$ and analyzed according to the procedure. A graph is plotted with a concentration on X-axis versus the response of a peak on Y-axis. The obtained correlation coefficient is 0.9998 and the detector response was found to be linear. The bias for $100 \%$ response was $1.42 \%$. The Table- 4 represents Linearity results and Fig- 13 shows Linearity graph

Table-4: Linearity Results

\begin{tabular}{c|c|c}
\hline Spike Level & Concentration ' $\mu \mathrm{g} / \mathrm{mL}$ & Peak Response \\
\hline $50 \%$ & 60.03846 & 844476 \\
\hline $75 \%$ & 90.05769 & 1225867 \\
\hline $100 \%$ & 120.05769 & 1617574 \\
\hline $125 \%$ & 150.09614 & 2038588 \\
\hline $150 \%$ & 180.11537 & 2454660 \\
\hline Correlation of coefficient (r) & 0.9998 \\
\hline \multicolumn{2}{c}{ Intercept (C) } & 22997.3 \\
\hline \multicolumn{2}{c}{ Slope (m) } & 13435.02 \\
\hline \multicolumn{2}{c}{ Bias at $100 \%$ response } & 1.42 \\
\hline
\end{tabular}

1094 
RASĀYAN J. Chem.

Vol. 14 | No. 2 |1087-1097| April - June | 2021

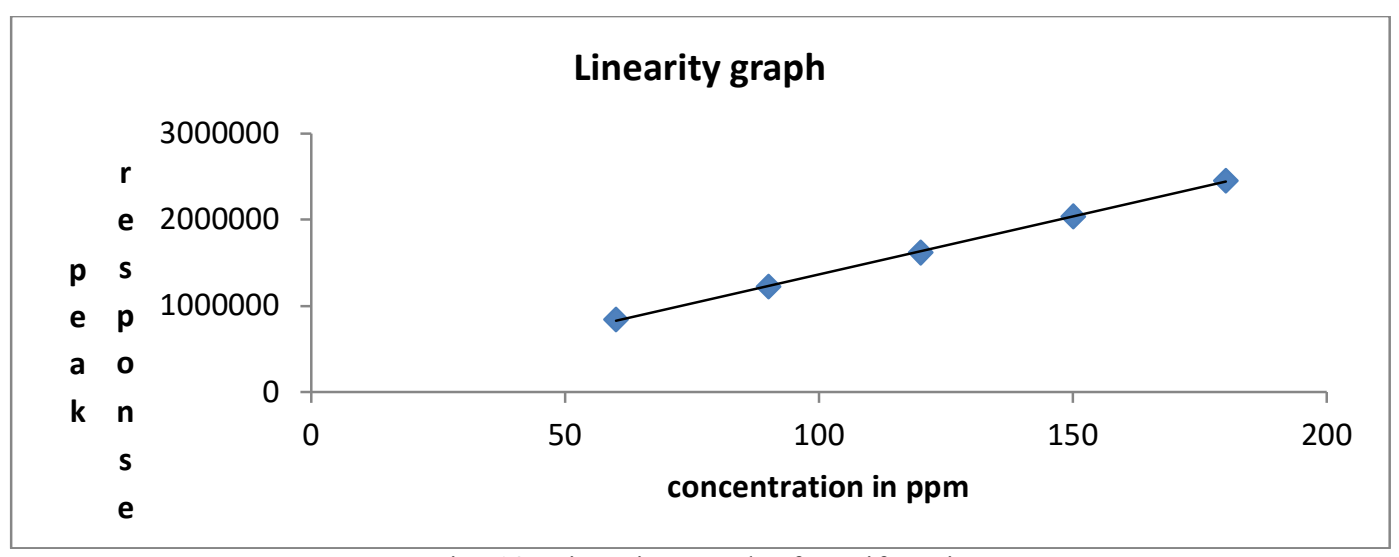

Fig.-13: Linearity Graph of Guaifenesin

\section{Accuracy}

Recovery studies are performed for Guaifenesin at 50\% to $150 \%$. Samples were prepared, with Placebo and Guaifenesin API equivalent to $50 \%, 75 \%, 100 \%, 125 \%$, and $150 \%$ of target concentration of the assay of Guaifenesin ER Tablet. Triplicate sample solutions were prepared for spike level 75\%, 100\% and 125\% and six preparations for $50 \%$ and $150 \%$ and assayed as per test method. The $\%$ recovery was found within the range of acceptable limits. The Recovery results are represented in Table-5.

Table-5: Recovery Results

\begin{tabular}{|c|c|c|c|}
\hline $\begin{array}{c}\text { Sample } \\
\text { Preparation }\end{array}$ & Recovery Spike Level & $\%$ Recovery & Mean \% Recovery \\
\hline 1 & $50 \%$ & 98.37 & \multirow{6}{*}{98.72} \\
\hline 2 & $50 \%$ & 97.81 & \\
\hline 3 & $50 \%$ & 98.42 & \\
\hline 4 & $50 \%$ & 100.00 & \\
\hline 5 & $50 \%$ & 97.73 & \\
\hline 6 & $50 \%$ & 99.98 & \\
\hline 1 & $75 \%$ & 99.09 & \multirow{3}{*}{99.08} \\
\hline 2 & $75 \%$ & 98.98 & \\
\hline 3 & $75 \%$ & 99.16 & \\
\hline 1 & $100 \%$ & 98.13 & \multirow{3}{*}{98.08} \\
\hline 2 & $100 \%$ & 98.12 & \\
\hline 3 & $100 \%$ & 97.99 & \\
\hline 1 & $125 \%$ & 98.20 & \multirow{3}{*}{98.86} \\
\hline 2 & $125 \%$ & 98.97 & \\
\hline 3 & $125 \%$ & 99.40 & \\
\hline 1 & $150 \%$ & 97.91 & \multirow{6}{*}{98.46} \\
\hline 2 & $150 \%$ & 97.68 & \\
\hline 3 & $150 \%$ & 98.50 & \\
\hline 4 & $150 \%$ & 98.41 & \\
\hline 5 & $150 \%$ & 99.39 & \\
\hline 6 & $150 \%$ & 98.89 & \\
\hline
\end{tabular}

\section{Ruggedness}

Solution stability of standard solutions performed at room temperature and refrigerator conditions. Solution stability of sample solutions performed at room temperature and in the refrigerator. Initially, two samples were prepared and kept on bench top (at room temperature) and in the refrigerator. Analysis was performed 
after day-1, after day-2 and after day-5. The standard and sample solutions are stable for 5 days on benchtop condition. Table- 6 represented the solution stability results.

\section{Robustness}

Robustness is evaluated for variations in mobile phase flow rate, $\mathrm{pH}$ of buffer in mobile phase and oven temperature of column. Done System suitability calculations and results are within the acceptable limits. The robustness results are represented in Table- 7 .

Table-6: Sample Solution Stability Results

\begin{tabular}{c|c|c|c|c|c}
\hline \multicolumn{5}{c}{ Room Temperature Results } \\
\hline \multirow{2}{*}{ Time in Days } & \multirow{2}{*}{ Standard Similarity Factor } & \multicolumn{2}{|c|}{$\%$ Assay of Test } & \multicolumn{2}{c}{ Difference from Initial Zero- } \\
\cline { 3 - 5 } & & Test-1 & Test-2 & Test-1 & Test-2 \\
\cline { 3 - 5 } & NA & 100.75 & 100.57 & NA & NA \\
\hline Initial Zero Day & 1.01 & 101.46 & 101.42 & 0.71 & 0.85 \\
\hline 1 & 1.01 & 101.02 & 100.38 & 0.27 & 0.19 \\
\hline 2 & 1.02 & 102.71 & 102.48 & 1.96 & 1.91 \\
\hline 5 & & & & & \\
\hline
\end{tabular}

Table-7: Robustness Results

\begin{tabular}{c|c|c|c|c}
\hline Variation & Robust Parameter & 5 inj. Area $\%$ RSD & USP Plate Count Avg. & USP Tailing Avg. \\
\hline \multirow{3}{*}{ Flow variation } & Actual $(1.0 \mathrm{ml} / \mathrm{min})$ & 0.1 & 9354 & 1.1 \\
\cline { 2 - 5 } & Low $(0.8 \mathrm{ml} / \mathrm{min})$ & 0.1 & 9958 & 1.1 \\
\cline { 2 - 5 } & High $(1.2 \mathrm{ml} / \mathrm{min})$ & 0.2 & 7334 & 1.1 \\
\hline \multirow{2}{*}{$\begin{array}{c}\text { Column oven } \\
\text { temperature }\end{array}$} & Actual $\left(40^{\circ} \mathrm{C}\right)$ & 0.0 & 8490 & 1.1 \\
\cline { 2 - 5 } & Low $\left(35^{\circ} \mathrm{C}\right)$ & 0.1 & 8455 & 1.1 \\
\cline { 2 - 5 } & High $\left(45^{\circ} \mathrm{C}\right)$ & 0.1 & 8649 & 1.1 \\
\hline \multirow{2}{*}{$\begin{array}{c}\text { pH of buffer in } \\
\text { mobile phase }\end{array}$} & Actual $(\mathrm{pH} \mathrm{3.0)}$ & 0.1 & 9354 & 1.1 \\
\cline { 2 - 5 } & Low $(\mathrm{pH} 2.8)$ & 0.1 & 8772 & 1.1 \\
\cline { 2 - 5 } & High $(\mathrm{pH} \mathrm{3.2)}$ & 0.1 & 8504 & \\
\hline
\end{tabular}

\section{CONCLUSION}

Successfully developed a stability-indicating liquid chromatographic method using reverse-phase mode and analytical method validation of the test method was done for the quantitative determination of guaifenesin present in the complex extended-release formulation matrix. This method provided selective quantification of Guaifenesin without interference from blank, placebo and impurities. Forced degradation studies show the discriminating nature, considering the analytical method as stability-indicating. The developed method was further validated with parameters specificity, precision, accuracy, linearity, ruggedness, and robustness according to ICH guidelines. The results of validation parameters are found satisfactory and met the acceptable limits. Hence, the developed method is stability-indicating and can be employed for quality control evaluation of pharmaceutical products.

\section{ACKNOWLEDGEMENT}

The authors are gratefully acknowledged to the Department of Chemistry and Centre for Advanced Energy Studies (CAES), KLEF (Deemed to be University), Vaddeswaram, Andhra Pradesh, India for providing the research facilities.

\section{REFERENCES}

1. H. H. Albrecht, P.V. Dicpinigaitis and E.P. Guenin, Multidisciplinary Respiratory Medicine, 12, 31(2017), DOI:10.1186/s40248-017-0113-4

2. P. Thangavelu, A.C .Grace and J. Murugesan, International Journal of Pharmaceutical and Biological Science, 10(2), 27(2020), DOI:10.22376/ijpbs

3. P. Swarupa, K.R.S. Prasad, K. Suresh Babu and J. V. Shanmukha Kumar, Rasayan Journal of Chemistry, 12(4), 2338(2019), DOI:10.31788/RJC.2019.1245438

4. R.S.C. Phani, K.R.S. Prasad and R.M. Useni, Indian Drugs, 56(2), 31(2019) 
5. R. M. Useni, A. Venkateswara Rao and Kasimala Bikshal Babu, Turkish Journal of Pharmaceutical Sciences, 16(4), 457(2018), DOI:10.4274/tjps.galenos.2018.34635

6. Somana Siva Prasad, G.V. Krishna Mohan. and A. Naga Babu, Asian Journal of Chemistry, 31(5), 1002(2019), DOI: 10.14233/ajchem.2019.21723

7. P. Kumar, G.V. Krishna Mohan. and Andraju Babu, Asian Journal of Chemistry, 31(10), 2215(2019), DOI: 10.14233/ajchem.2019.22069

8. P. Salomi, D. Nayak, T.Vimalakannan, K. Reddy, International Journal of Research in Pharmaceutical Chemistry and Analysis, 1(1), 18(2018), DOI:10.33974/ijrpca.v1i1.25

9. N. Kalpana, J.V. Shanmukha Kumar and D. Ramachandran, Asian Journal of Pharmaceutical and Clinical Research, 11(2), 164(2018), DOI:10.22159/ajpcr. 2018.v11i2.22465

10. Nada S. Abdel Wahab, Eglal A. Abdel Aleem, Arabian Journal of Chemistry, 10(2), 2896(2013), DOI:10.1016/j.arabjc.2013.11.019

11. M.L. Wilcox, J.T. Stewart, Journal of Pharmaceutical and Biomedical Analysis, 23(5), 909(2000), DOI: 10.1016/s0731-7085 (00)00359-9

12. I. Demian, Chirality, 5(4), 238(1993), DOI:10.1002/chir.530050409

13. G. Grosa., ED Grooso, R. Russo, G. Allergrone, Journal of Pharmaceutical and Biomedical Analysis, 41(3), 798(2006), DOI:10.1016/j.jpba.2006.01.026

14. A.Ozdemir, H.Aksoy, E.Dinc, D. Baleanu, S.Dermis, Revue Romaine De Chimie, 51(2), 117(2006)

15. M.Senthilraja, P.Giriraj, Asian Journal of Pharmaceutical and Clinical Research, 4(2), 13(2011)

16. S.Suzen, C.Akay, S.Cevheroglu, Farmaco, 549(10), 705(1999)

17. S.M. Amer, S.S. Abbas, M.A. Shehata, N.M. Ali, Journal of Association of Official Analytical Collaboration (AOAC) International, 91(2), 276(2008), DOI:10.1093/jaoac/91.2.276

18. V.Galli, C. Barbas, Journal of Chromatography A, 1048(2), 207(2004), DOI: 10.1016/J.CHROMA.2004.07.050

19. P. Sunil Reddy, K. Sudhakar Babu, N. Kumar, and Y.V.V. Sasi Sekhar, Pharmaceutical Methods, 2(4), 229(2011), DOI:10.4103/2229-4708.93391

20. S.Valavala, N.Seelam, S.Tondepu and S.Vivekanandan, Asian Journal of Chemistry, 29(11), 2434(2017), DOI:10.14233/ajchem.2017.20729

21. R.V. Athota, S.K. Jagarlapudi, M.R. Singampalli, Journal of Applied Pharmaceutical Science, 7(3), 48(2017), DOI:10.7324/JAPS.2017.70308

22. R. S. C. Phani, K. R. S. Prasad, R.M. Useni, Oriental Journal of Chemistry, 32(2), 1193(2016), DOI: $10.13005 / \mathrm{ojc} / 320246$

23. R. S. C. Phani, K. R. S. Prasad, R.M. Useni, Asian Journal of Chemistry, 29(11), 2565(2017), DOI:10.14233/ajchem.2017.20899

24. G. Qing-hua, Z. Zhen, Z. Xiao-jin, M. Li-li, D. Cun-gang, Chinese Journal of Pharmaceuticals, 44(13), 1025(2009)

25. R. M. Gudipati, J. E. Wallace, S. A. Stavchansky, Analytical Letters, 24(2), 265(1991), DOI: $10.1080 / 00032719108052902$

26. X. Chen, J. Huang, Z. Kong, D. Zhong, Journal of Chromatography B, 817(2), 263(2005), DOI: 10.1016/j.jchromb.2004.12.011

27. ICH Q1A (R2), Stability Testing of new Drug Substances and Products

28. ICH Q1B, Photo Stability Testing on New Drug Substances and Products

29. ICH Q2 (R1), Validation of Analytical Procedures: Text and Methodology

[RJC-6219/2020] 